\title{
ASO Author Reflections: Real-World Incidence of Peritoneal Carcinomatosis After Colon Cancer Resection and Why It Matters
}

\author{
Audrey H. Choi, MD ${ }^{1}$, and Maheswari Senthil, $\mathrm{MD}^{2}$ \\ ${ }^{1}$ Division of Surgical Oncology, Department of Surgery, Loma Linda University Health, Loma Linda, CA; ${ }^{2}$ Department of \\ Surgery, University of California at Irvine, Orange, CA
}

Combined advances in molecular profiling and systemic targeted therapies have steadily improved overall outcomes for patients with metastatic colon cancer. Although the impact of these advances is largely observed for patients with visceral metastases, peritoneal carcinomatosis (PC) continues to remain a significant therapeutic challenge.

The scientific community must contend with several issues to make a meaningful impact on the outcomes for patients with PC. One of the key factors repeatedly shown to make a difference in survival outcomes is the extent of peritoneal disease burden, often described as the peritoneal cancer index (PCI). Although PRODIGE 7, a randomized controlled trial, failed to demonstrate a survival benefit of heated intraperitoneal oxaliplatin chemotherapy for patients who underwent cytoreduction (CRS), it unequivocally demonstrated the benefit of CRS, with a reported median survival of nearly 42 months for the entire study population. ${ }^{1}$ As the role of CRS is expanding, so is the need for early detection when the PCI is low, hence it is vital to understand both the incidence of PC in surgically resected colon cancer and the impact of high-risk features on this incidence. To date, the literature has presented a wide range of PC incidences after curative resection, ranging from 5 to $20 \%{ }^{2,3}$ In our study of two large tertiary referral centers, the overall PC incidence after resection of stages 2 and 3 colon cancers was $6.4 \% .^{4}$ The patients who

(C) Society of Surgical Oncology 2020

First Received: 10 June 2020;

Published Online: 6 July 2020

M. Senthil, MD

e-mail: m.senthil@uci.edu had selected high-risk features (pT3N0-2 with mucinous/ signet ring components, $\mathrm{pT} 4, \mathrm{pN} 1 \mathrm{c}$, or perforation) demonstrated a significantly higher $\mathrm{PC}$ incidence than the patients without high-risk features $(9.7 \%$ vs $2.8 \%)$. We believe that the data presented in this study provide valuable information for the design of future trials attempting to identify PC at early stages. Furthermore, it also behooves us to explore the molecular and biologic reasons for the observed predisposition to PC in mucinous and signet ring cancers. In the future, collective contributions through clinical and translational research will help us move the needle toward better outcomes for patients with PC.

DISCLOSURE The authors declare that they have no conflict of interest.

\section{REFERENCES}

1. Quenet F, Elias D, Roca L, et al. A UNICANCER phase III trial of hyperthermic intra-peritoneal chemotherapy (HIPEC) for colorectal peritoneal carcinomatosis (PC): PRODIGE 7. J Clin Oncol. 2018;36(18 Suppl):LBA3503.

2. Jayne DG, Fook S, Loi C, Seow-Choen F. Peritoneal carcinomatosis from colorectal cancer. Br J Surg. 2002;89:1545-50.

3. Koppe MJ, Boerman OC, Oyen WJ, Bleichrodt RP. Peritoneal carcinomatosis of colorectal origin: incidence and current treatment strategies. Ann Surg. 2006;243:212-22.

4. Choi AH, Farzaneh C, Kejriwal N, Calidas A, Cordero-Caban K, Roman M, Kwong MLM, et al. Rate of peritoneal carcinomatosis in resected stage ii and iii colon cancer. Ann Surg Oncol. 2020. https://doi.org/10.1245/s10434-020-08689-y.

Publisher's Note Springer Nature remains neutral with regard to jurisdictional claims in published maps and institutional affiliations. 